\title{
Editorial
}

\section{Functional Differential and Difference Equations with Applications}

\author{
Josef Diblík, ${ }^{1,2}$ Elena Braverman, ${ }^{3}$ István Györi, ${ }^{4}$ \\ Yuriy Rogovchenko, ${ }^{5,6}$ Miroslava Růžičková, ${ }^{7}$ and Ağacık Zafer ${ }^{8}$ \\ ${ }^{1}$ Department of Mathematics and Descriptive Geometry, Faculty of Civil Engineering, Brno University of \\ Technology, 60200 Brno, Czech Republic \\ ${ }^{2}$ Department of Mathematics, Faculty of Electrical Engineering and Communication, Brno University of \\ Technology, 61600 Brno, Czech Republic \\ ${ }^{3}$ Department of Mathematics and Statistics University of Calgary, 2500 University Drive NW, \\ Calgary, AB, Canada T2N 1N4, Canada \\ ${ }^{4}$ Department of Mathematics, Faculty of Information Technology, University of Pannonia, \\ 8200 Veszprém, Hungary \\ ${ }^{5}$ Department of Mathematical Sciences, University of Agder, Post Box 422, 4604 Kristiansand, Norway \\ ${ }^{6}$ Department of Mathematics and Mathematical Statistics, Umeå University, 90187 Umeå, Sweden \\ ${ }^{7}$ Department of Mathematics, University of Žilina, 01026 Žilina, Slovakia \\ ${ }^{8}$ Department of Mathematics, Middle East Technical University, 06800 Ankara, Turkey
}

Correspondence should be addressed to Josef Diblík, diblik@feec.vutbr.cz

Received 1 November 2012; Accepted 1 November 2012

Copyright (C) 2012 Josef Diblík et al. This is an open access article distributed under the Creative Commons Attribution License, which permits unrestricted use, distribution, and reproduction in any medium, provided the original work is properly cited.

This special issue may be viewed as a sequel to Recent Progress in Differential and Difference Equations edited by the four members of the present team and published by the Abstract and Applied Analysis in 2011. Call for papers prepared by the Guest Editors and posted on the journal's web page encouraged the submission of state-of-the-art contributions on a wide spectrum of topics such as asymptotic behavior of solutions, boundedness and periodicity of solutions, nonoscillation and oscillation of solutions, representation of solutions, stability, numerical algorithms, computational aspects, and applications to real-world phenomena. Our invitation was warmly welcomed by the mathematical community-more than one hundred manuscripts addressing important problems in the qualitative theory of functional differential and difference equations were submitted to the editorial office and went through a thorough peer-refereeing process. A thirty-eight carefully selected research articles for this special issue reflect modern trends and advances in functional differential and difference equations. Eighty-seven authors from seventeen countries (Bulgaria, China, Czech Republic, Egypt, Germany, Greece, Korea, Libya, Poland, Saudi Arabia, Slovak Republic, Spain, Thailand, Turkey, Ukraine, United Kingdom, and USA) have contributed to the success 
of this thematic collection of papers dealing with various classes of delay differential equations, dynamic equations on time scales, partial differential equations, neutral functional differential equations, systems with $p$-Laplacian, stochastic differential equations, and related topics.

For many decades, the stability problems has attracted attention of researchers working with the qualitative theory of differential, functional differential, and difference equations. In this issue, the reader will find papers addressing stability of nonlinear differential systems with random parameters, robust stability of interval neural networks with discrete and distributed time delays, mean square exponential stability of stochasticswitched systems with interval time-varying delays, global exponential stability of periodic solutions to neural networks and impulsive neural networks with time-varying delays, and stability of impulsive stochastic functional differential systems.

Important directions in the modern qualitative theory of differential equations include periodicity, almost periodicity, oscillation, and nonoscillation of solutions to various classes of equations. This special issue contains papers that are concerned with the existence of periodic solutions to nonlinear dynamic equations on time scales, oscillation of secondorder quasilinear neutral functional differential equations, existence of periodic solutions to difference systems with a $p$-Laplacian, interval oscillation criteria for second-order-mixed nonlinear impulsive differential equations with delay, existence of positive periodic solutions to first-order neutral functional differential equations with periodic delays, existence of almost periodic solutions to parabolic inverse Cauchy problems, bounded oscillation of forced nonlinear neutral differential equations, and existence of periodic solutions to Duffingtype $p$-Laplacian equations with multiple constant delays. Two papers in this collection deal with the asymptotic behavior of solutions to a class of two-dimensional differential systems with a finite number of nonconstant delays and with the properties of smooth solutions to a class of iterative functional differential equations.

It is for sure that existence of positive solutions is important for many applied problems. In this special issue, the reader can find contributions that address positivity of solutions to nonlinear two-dimensional difference systems with multiple delays, existence of positive bounded solutions to third-order discrete equations, partial difference equations with delays, Neumann boundary value problems for second-order impulsive differential equations in Banach spaces, neutral differential equations, existence and multiplicity of positive solutions to a class of nonlinear discrete fourth-order boundary value problems, and existence of positive monotonic solutions to nonlocal boundary value problems for a class of second-order functional differential equations. Estimates for positive solutions to discrete linear equations with a single delay are also established in one of the papers.

Several articles deal with important aspects of the theory of boundary value and initial value problems providing the analysis of a class of boundary value problems for a system of autonomous second-order linear partial differential equations of parabolic type with a single delay and Dirichlet problems with an indefinite and unbounded potential and concaveconvex nonlinearities. In other papers included in this special issue, linear homogeneous partial differential equations with entire solutions represented by Laguerre polynomials are studied, monotone-iterative methods for initial value problems for differential equations with "maxima" and initial time differences are developed, necessary and sufficient conditions for the existence of solutions to a class of discrete second-order boundary value problems are derived, existence of one-signed solutions to some discrete second-order periodic boundary value problems is established, and optimal conditions for the existence and uniqueness of 
solutions to a class of nonlocal boundary value problems for linear homogeneous secondorder functional differential equations with piecewise constant arguments are obtained.

The last but not the least, this issue features a number of publications that report recent progress in the analysis of problems arising in various applications. In particular, dynamics of delayed neural network models consisting of two neurons with inertial coupling were studied, properties of a stochastic delay logistic model under regime switching were explored, and analysis of the permanence and extinction of a single species with contraception and feedback controls was conducted. Other applied problems addressed in this special issue regard Cohen-Grossberg BAM neural networks with time-varying delays, adaptive observer-based fault estimation for stochastic Markovian jumping systems, hematopoiesis models, Lotka-Volterra systems, and finite-time attractivity for diagonally dominant systems with off-diagonal delays.

It is certainly impossible to provide in this short editorial note a more comprehensive description for all articles in the collection. However, the team of the Guest Editors believes that results included in this volume represent significant contemporary trends in the qualitative theory of ordinary, functional, partial, impulsive, dynamic, stochastic differential, and difference equations and in applications. We hope that this special issue will serve as a source of inspiration for researchers working in related areas providing specialists with a wealth of new ideas, techniques, and unsolved problems.

Josef Diblik

Elena Braverman

István Györi

Yuriy Rogovchenko

Miroslava Růžičková

A ğacık Zafer 


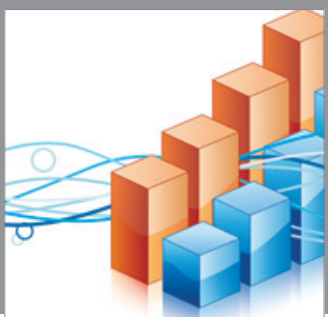

Advances in

Operations Research

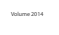

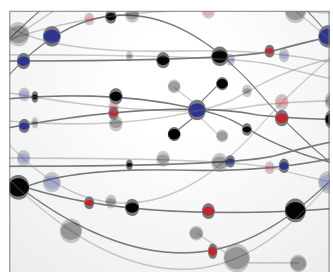

\section{The Scientific} World Journal
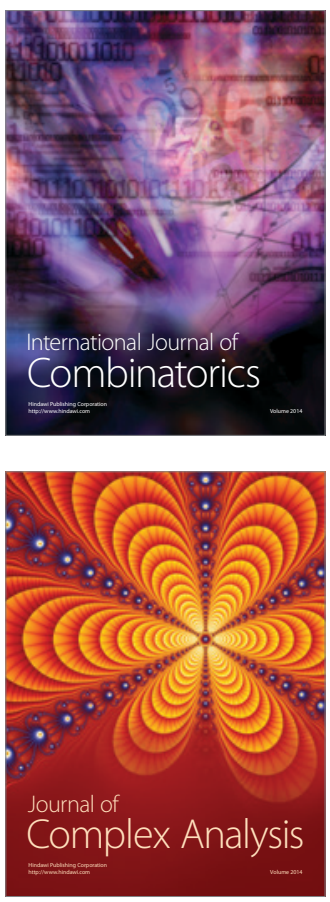

International Journal of

Mathematics and

Mathematical

Sciences
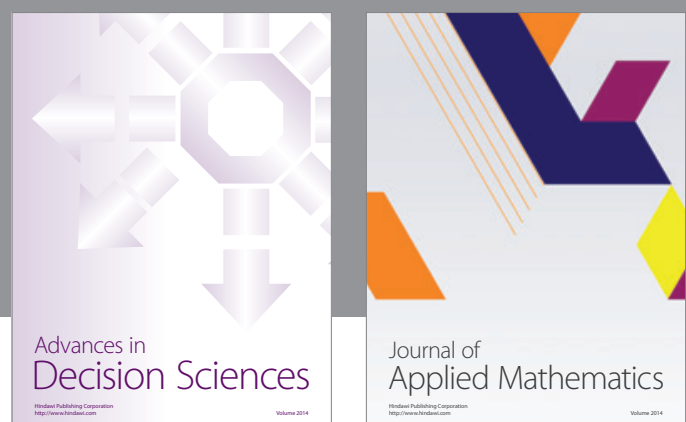

Journal of

Applied Mathematics
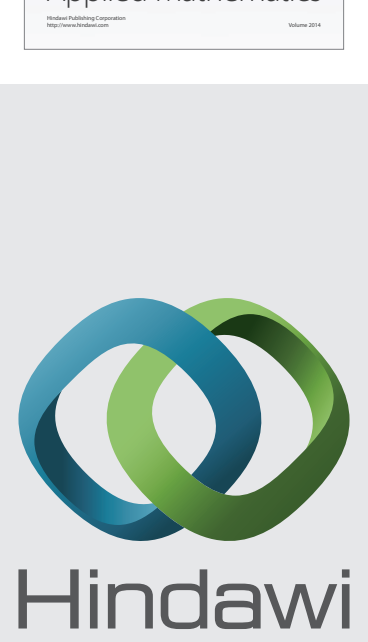

Submit your manuscripts at http://www.hindawi.com
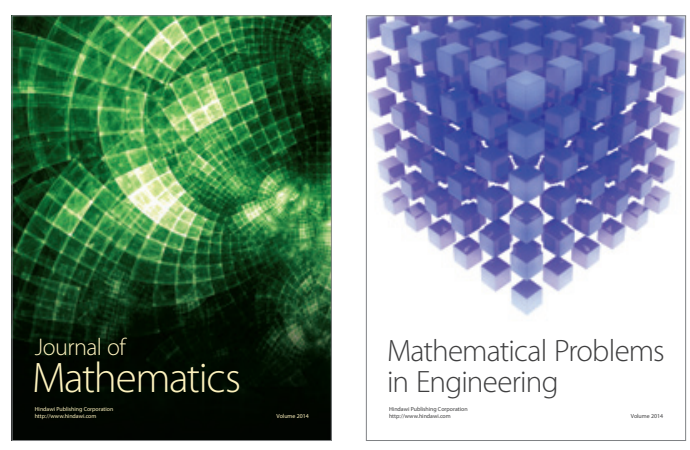

Mathematical Problems in Engineering
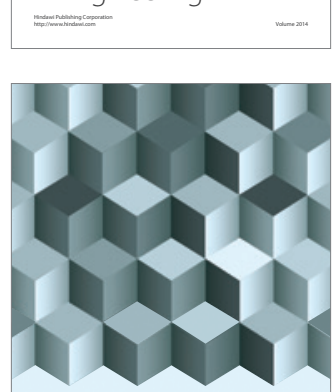

Journal of

Function Spaces
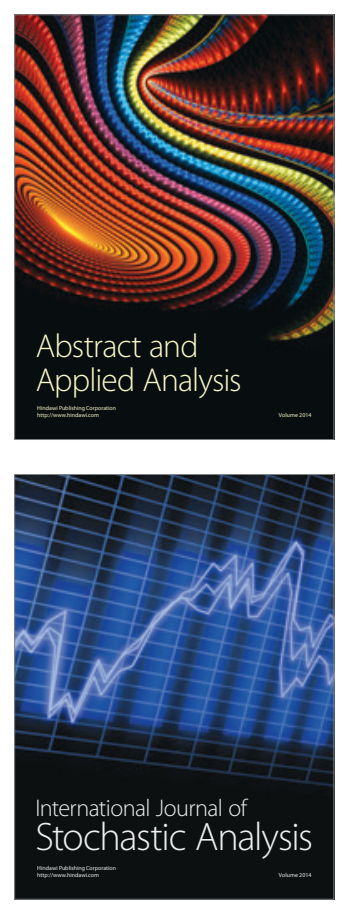

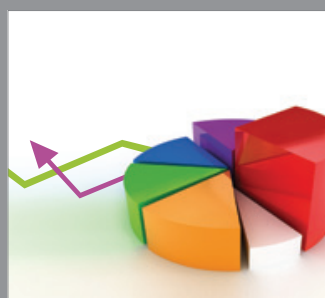

ournal of

Probability and Statistics

Promensencen
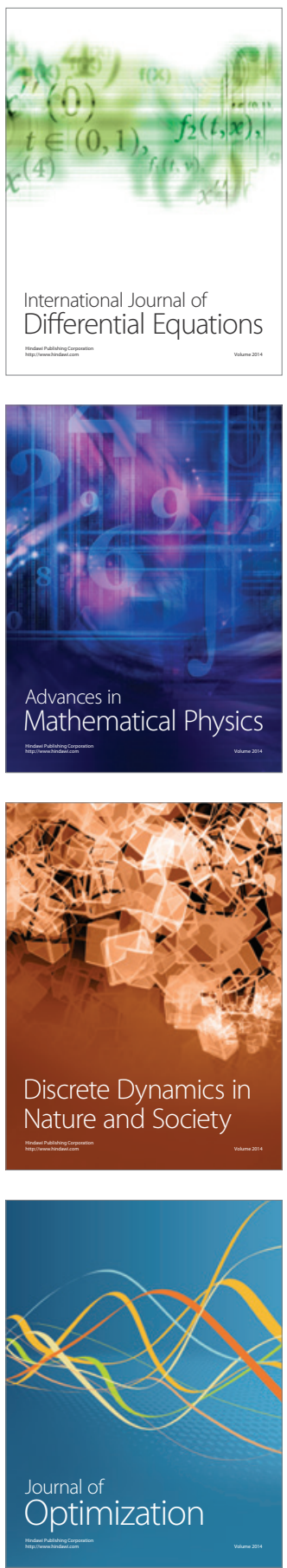